\title{
Uf
}

Volume: 18 Issue: 4 Year: 2021

\section{The role of perceived organizational support in work-leisure conflict}

\section{İş serbest zaman çatışmasında algılanan örgütsel desteğin rolü}

\author{
Serkan Kurtipek ${ }^{1}$ \\ Tebessüm Ayyıldız Durhan ${ }^{2}$ \\ Nuri Berk Güngör ${ }^{3}$
}

\begin{abstract}
In this study, it is aimed to examine the effect of perceived organizational support of employees on the level of work-leisure conflict. The working group of the research consists of the personnel of the Ministry of Youth and Sports, who are working in Ankara. In addition to the personal information form, the "Work-Leisure Conflict Scale" and "Perceived Organizational Support Scale" were used in the data collection phase of the research. T-test for comparing the total scores obtained from the scales with the variables of regular activity participation, daily leisure time sufficient; Descriptive statistics were used to determine the scores obtained from the scales, Pearson Moment Correlation Test and Regression Analysis research were used to determine the relationship between the variables. For this study, the internal consistency coefficient for WLC was determined as .95, and the internal consistency coefficient for POS was determined as .90. The findings show that the participants showed an average WLC level, on the other hand, they had POS scores above the average. On the other hand, it was found that there were significant differences between the
\end{abstract}

Özet

Çalışmada işgörenlerin algılanan örgütsel desteğin iş-serbest zaman çatışma düzeyine etkisinin incelenmesi amaçlanmıştır. Araştırmanın çalışma grubunu, Ankara ilinde görevlerini sürdürmekte olan Gençlik ve Spor Bakanlığ1 personeli oluşturmaktadır. Araştırmada veri toplama aşamasında kişisel bilgi formunun yanı sıra "İş-Serbest Zaman Çatışma Ölçeği” ile "Alg1lanan Örgütsel Destek Ölçeğì" kullanılmıştır. Ölçeklerden elde edilen toplam puanların düzenli etkinlik katılımı, günlük serbest zaman süresinin yeterli görülme değişkenleri ile karşılaştırılmasında T-testi; ölçeklerden elde edilen puanların belirlenmesinde betimsel istatistikler, değişkenler arasındaki ilişkinin belirlenebilmesi için Pearson Momentler Çarpımı Korelasyonu Testi ve Regresyon Analizi araşturma kullanılmıştır. Bu çalışma için ISZÇ için iç tutarll1ık katsayısı .95, AÖD için iç tutarllık katsayısı .90 olarak belirlenmiştir. Elde edilen bulgular katılımcıların ortalama İSZÇ düzeyi gösterdikleri, buna karşılık ortalamanın üzerinde AÖD puanları ortaya koyduklarını göstermektedir. Diğer yandan katılımciların

1 Assoc. Prof. Dr., Gazi University, Sports Science Faculty, Department of Sport Management, serkankurtipek@gazi.edu.tr (D) Orcid ID: 0000-0002-4791-9482

2 Dr., Gazi University, Sports Science Faculty, Recreation Department, tebessum@gazi.edu.tr (iD) Orcid ID: 0000-0003-2747-6933

3 Assoc. Prof. Dr., Balıkesir University, Sports Science Faculty, Deparment of Sport Management, nuriberkgungor@gmail.com (iD) Orcid ID: 0000-0002-6579-9146 
Kurtipek, S., Ayyıldız Durhan, T., \& Güngör, N. B. (2021). İşs serbest zaman çatışmasında algılanan örgütsel desteğin rolü. Journal of Human Sciences, 18(4), 715-727. doi:10.14687/jhs.v18i4.6235

participants' daily leisure time, regular activity participation variables, and WLC and POS levels, there was a negative and low-level relationship between WLC and POS ( $\mathrm{r} 1=-.231$, $\mathrm{p}<.01)$. It has been determined that POS affects WLC. The findings reveal important data to draw attention to the perceived organizational support of employees in reducing work-leisure conflict.

Keywords: Work, leisure, conflict, perceived organizational support.

(Extended English summary is at the end of this document) günlük serbest zaman süresi, düzenli etkinlik kattlımı değişkenleriyle İSZÇ ve AÖD düzeyleri arasında anlamlı farkllıklar olduğu, İSZÇ ve AÖD arasinda negatif yönlü ve düşük düzeyde bir ilişkinin olduğu ve $\left(\mathrm{r}_{1}=-.231, \mathrm{p}<.01\right)$. AÖD’nin İSZÇ’yi etkilediği belirlenmiştir. Bulgular işgörenlerin iş serbest zaman çatışmasını azaltmada algılanan örgütsel desteğe dikkat çekmek üzere önemli veriler ortaya koymaktadır.

Anahtar kelimeler: İş, serbest zaman, çatışma, alg1lanan örgütsel destek.

\section{GİRİŞ}

İnsanların yaşamlarında pek çok role sahip olmasından dolayı ilgili rollerdeki başarıları veya başarısızlıkları bu ilişkilerin niteliğini belirlemektedir. Bir takım rollerin artışı diğer bazı rollerin durumuna etki etmekte ve dolayısıyla çeşitli rollerin yerine getirilmesini sınırlayabilmektedir. Böyle bir durum yaşandığında insanlar ciddi çatışma, karmaşa veya belirsizlikler ile mücadele etmek durumunda kalmaktadır. Bundan ötürü insanlar hayatlarının belirli kesitlerinde üstlendikleri veya üstlenme durumunda kaldıkları rolleri yerine getirirken denge sağlamaya gayret göstermelidir (Özdevecioğlu ve Çakmak Doruk, 2009). Bu sebeple, bireylerin yaşam dengesini kurması sürecinde belirli düzeyde serbest zamana sahip olabilmesi ve bu zamanında özgürce etkinliklere katılabilmesi, hayattan keyif alabilmesi için bu sınırlanı iyi yönetebilmesi beklenmektedir (Lin, Wong \& Ho, 2015; Sop, 2014). Birey, fiziksel veya zihinsel olarak serbest zaman etkinliklerine tam olarak katilamiyorsa ya da kendisine serbest zaman yaratamıyorsa, bunun nedeni işin kişisel yaşama müdahale etmesi olabilir. $\mathrm{Bu}$ açıdan bakıldı̆̆ında iş, kişinin serbest zaman etkinliklerine katılma becerisini engellediğinde, çatışmalara neden olmaktadır (Meier ve diğ., 2021). Haftada 48 saatten fazla çalışan bireylerin iş serbest zaman dengesini verimli biçimde kurgulamasının zorluklarının altı çizilmektedir (Guest, 2001; Lin ve diğ., 2013).

Sanayileşme ve bilgisayarlaşmanın bir sonucu olarak, insanlar serbest zaman etkinliklerine katılmak için eskiye nazaran daha fazla imkana sahip olmuştur. Bu süreç serbest zaman alanının önemini kavranmasına ve bu alana olan ilgiyi artırmaya yol açmışır. Serbest zamanların öneminin algılanması ve işle ilgili değerlerden ziyade istikrarlı bir şekilde ilerlemesi fikri, çağdaş toplumdan doğmaktadır. Bu sebeple, serbest zaman çalışma alanlarıyla giderek daha fazla rekabet etmektedir. Bu durum, iş ve serbest zaman alanlarından gelen rol yoğunluğunun karşlıklı olarak uyum içerisinde olmaması durumu ve iş-serbest zaman çatısması araştırmasını önemli kıldığı roller arası çatışmalara neden olmaktadır (Tsaur, Liang \& Hsu, 2012). Çünkü iş ve serbest zaman hayatın tamamen farklı iki yönüdür. Her ikisi de kişisel zaman ve enerji ile sınırlı olduğundan, çatışabilir veya rekabet edebilirler (Lin, Wong \& Ho, 2013; Wong \& Lin, 2007).

İş-serbest zaman çatışması daha sonra hizmet çalışanlarının iş rollerinin diğer yaşam rolleri üzerindeki hakimiyeti veya çalısanların iş talepleri nedeniyle zaman, enerji ve serbest zaman firsatlarının azalmasına neden olan enerji tükenmesi olarak tanımlanır (Wong \& Lin, 2007). Bir diğer tanıma göre; çalışanlar, enerji ve zaman gibi değerli kaynaklarını tüketen ve onları profesyonel rollerini yerine getiremez ve yeterli serbest zaman etkinliklerine sahip olamaz hale getiren yüksek iş yüküne maruz kaldıklarında ortaya çıkan bir rol arası çatışma biçimidir (Mansour \& Tremblay, 2016). Aynı zamanda iş-serbest zaman çatışması; iş ve serbest zaman alanlarında ortaya çıkan rol yoğunluğu çeşitli 
Kurtipek, S., Ayyıldız Durhan, T., \& Güngör, N. B. (2021). İş serbest zaman çatışmasında algılanan örgütsel desteğin rolü. Journal of Human Sciences, 18(4), 715-727. doi:10.14687/jhs.v18i4.6235

hususlarla ilişkili olarak uyum içinde olmadığı bir rol arası çatışma biçimi şeklinde nitelendirilmektedir. (Mansour \& Mohanna, 2018; Shi, Wang \& Li, 2021; Tsaur, Liang \& Hsu, 2012).

Şekil 1: İş-Serbest zaman çatışmasının boyutları

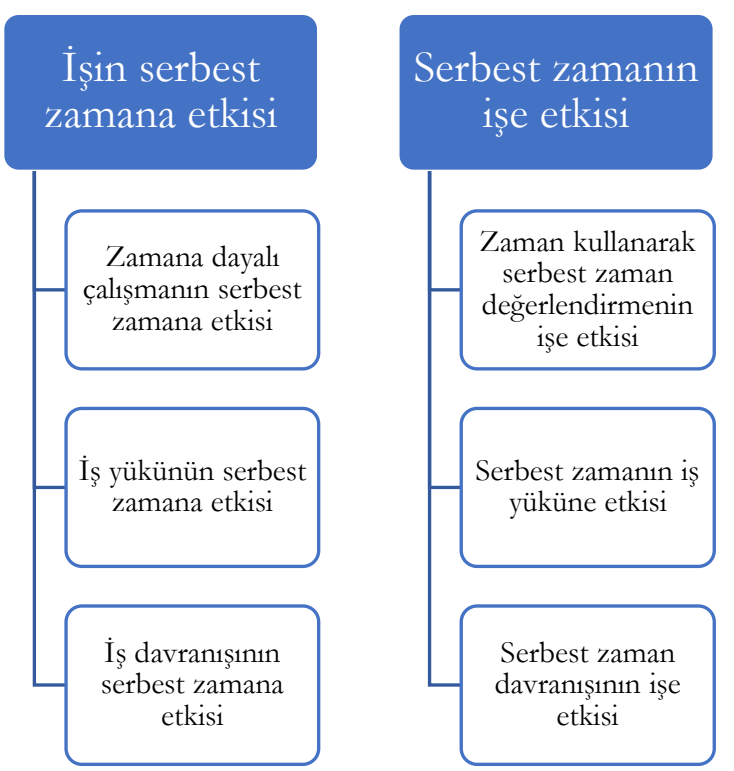

Kaynak: Tsaur, Liang ve Hsu'dan (2012) uyarlanmıstır.

Serbest zamandan işe geçen etki, serbest zaman faaliyetleri esnasında elde edilen olumlu duygu durum veya tutumun işe pozitif şekilde yansımasıyla sonuçlanmaktadır. İşten serbest zamana aktarım ise bireyin iş faaliyetlerine katılımının, serbest zaman faaliyetleri sırasında bilgilere erişim gibi sosyal kaynakları sağlamada olumlu yansıma oluşturur (Liang, 2020). Diğer taraftan iş-serbest zaman çatışması, işe bağlllı̆ı sürdürmek için gerekli olan psikolojik kaynakları tüketebilir (Jun \& Kyle, 2011). Wang \& Shi, 2020). Dolayısıyla işgörenlerin serbest zamanındaki artışla ilgili bütün girişimler, iş ile serbest zaman arasında yaşanan çatışmanın yoğunluğunu aza indirmeye dair önemli göstergeler olarak değerlendirilmektedir (Sop, 2014). Yaşanabilecek tüm bu olumsuzlukların çeşitli destek mekanizmalarıyla aşılması söz konusu olabilir.

Pek çok açıdan sosyal bir varlık olarak nitelendirilen insan, onaylanmak, takdir görmek, desteklenmek ve sayg1 duyulmak, toplumda bir gruba ve önemli başarılara sahip olmak gibi gereksinimlerini hayat boyu sürdürme ve bu hedeflere ulaşıp haz alma durumundadır (Üren \& Çorbacıoğlu, 2012). İşverenlerin de iş hayatında işgöreninin saygı duyulma, takdir görme gibi destek alanlarına katkı sunması, sosyal ve duygusal gereksinimlerine yanıt veren bir yönelim göstermesi çalışanın örgüt içinde kendi varlığını sürdürmesi noktasında gayretli ve tamahkar olmasını sağlamaktadır. Ayrıca kurumun da sürdürülebilirliğinin sağlanması, gelişmesi anlamında benimseyen bir duruş ortaya koyacaktır. Bu doğrultuda etkileşimli olarak sürdürülebilirliklerinin ve ilişkilerinin olduğu ifade edilebilir (Erkoç, 2015).

Çalışanların iş serbest zaman çatışmasını önlemede algıladıkları destek faktörlerinin çalıştıkları kurum özelinde olması, alg1lanan örgütsel destek unsurunu ön plana çıkartmaktadır. Bu doğrultuda çalışan bireylere yönelik kurumdaki işgörenin sosyal ve duygusal gereksinimlerine yanıt vermesi ve iyiliğine özen göstermesi, işgörenin de kurumun gereksinimlerini ve hedeflerini gerçekleştirmek adına daha fazla çalışmasını ve kuruma yönelik negatif tutumdan uzaklaşmasına sebebiyet verecektir (Kerse \& Karabey, 2017).

Örgütsel desteğe göre; işgörenler kurumların hedeflerini elde etme noktasında veya kurumun kazanımlarının fazlalaştırılması hususuna yardımcı olmak ve kuruma olan aidiyet duygularının fazlalaşması için kurum içinde önemli bir yerde olduklarını hissetmek isterler (Büyükgöze \& Kavak, 2017; Büyükyılmaz \& Çakmak, 2014; Tamer \& Bozaykut Bük, 2020) aynı zamanda kendilerini 
Kurtipek, S., Ayyıldız Durhan, T., \& Güngör, N. B. (2021). İş serbest zaman çatışmasında algılanan örgütsel desteğin rolü. Journal of Human Sciences, 18(4), 715-727. doi:10.14687/jhs.v18i4.6235

güvende hissetmek isterler (Özdevecioğlu, 2003). Bu durumunda performansa yansımas1 muhtemeldir (Parasız, Koç, Ilgar \& Şahin, 2017; Uğur \& Güngör, 2021; Uğur \& Yenel, 2007). Dolayısıyla örgütsel destek algisı, çalışanların bağlı oldukları kurum yoluyla sağlanan faydaya, refahlarına ve çalışma azmine verilen değerin algılanması olarak betimlenebilir (Tanrıverdi \& Kılıç, 2016).

Algılanan örgütsel destek, çalışanların, çalıştıkları kurumun sunduğu desteğe ve ne düzeyde önemsediğine yönelik içselleştirdikleri duygulardır (Güney, Akalın \& İlsev, 2007). Bir diğer deyişle algılanan örgütsel destek işgörenlerin, kuruluşlanının yaptıkları işe değer verdiğine ve çalışanların refahını önemsediğine inanmalarının genel derecesi olarak tanımlanabilir (Eisenberger ve diğ., 1986; Kurtosis ve dĭg., 2017). Algılanan örgütsel desteğin işgörenlerin iş süreçlerinde bekledikleri davranışlardan olduğu, böylelikle iş görenlerin kurumları ile ilişkilerini güçlendirdikleri ve dolayısıyla kendilerini örgütün bir mensubu olarak gördükleri söylenebilir (Afacan Fındıklı, 2014).

İsgörenlerin kurumlarından algıladıkları destek, onların rol ötesi tutumlar göstermelerine sebep olabilir (Akgündüz ve Çakıcı, 2015). İşe bağlanmalarına, verimli olmak için ekstra çaba harcamalarına sebep olabilir. Dolayısıyla olumsuz davranış kalıplarından ziyade algılanan örgütsel desteğin artmasıyla çeşitli çatışmaların da ortadan kalktı̆̆ı ifade edilebilir. Bu çatışmalardan biri olan iş serbest zaman çatışmasını önlemede alg1lanan örgütsel desteğin etkisinin olduğunu söylemek mümkündür.

Alg1lanan örgütsel destek unsurunda ortak durum; algılanan örgütsel desteğin işgörenin yaptıklarına değer sunulmasına, refahının ön planda tutulmasına ve gereksinimlerinin karşılanmasına dair alg1 durumudur (Kerse \& Karabey, 2017). Bu doğrultuda serbest zamanlardaki kaynak kullanımının kısıtlanması, iş yükünün artırılması alg1lanan örgütsel destekteki azalma ile mümkün görünmektedir. İşverenlerin çalışanlarına uzun çalışma saatleri boyunca, hatta hafta sonu tatilleri gibi süreler çerçevesinde iş sorumluluğu yüklemesi iş serbest zaman çatş̧masına neden olabilecek önemli faktörler arasındadır. İsgörenlerin algılanan örgütsel desteğin iş-serbest zaman çatışma düzeyine etkisinin incelenmesi amaçlandığı çalışma kapsamında iş serbest zaman çatışma düzeyleri incelenirken algılanan örgütsel desteğin iş serbest zaman çatışmasını etkileme durumu analiz edilmiştir. Aynı zamanda iş serbest zaman çatışmasını ve algılanan örgütsel desteği çeşitli değişkenlerin farklılaştırma durumları incelenmiştir.

\section{METERYAL VE METOT}

\section{Araştırma Modeli}

Gençlik ve Spor Bakanlığı personelinin iş-serbest zaman çatışma düzeyinin alg1lanan örgütsel desteğe etkisinin incelendiği bu araştırma, tarama modelinin kullanıldığı betimsel bir yapıdadır. Bu model, iki ya da daha fazla değissken arasındaki değişimin varlı̆̆ını veya derecesini ortaya koymayı hedeflemektedir (Karasar, 2013).

\section{Çalışma Grubu}

Araştırmanın çalışma grubunu; 2021 yllında Ankara ilinde görevlerini sürdürmekte olan 140’1 (\%63.3) erkek, 81’i (\%36.7) kadın Gençlik ve Spor Bakanlığı personeli oluşturmaktadır. Çalışma grubu, amaçlı örnekleme yöntemlerinden ölçüt örnekleme metodu kullanılarak oluşturulmuştur. Katıllımcıların 112 'si (\%50.7) günlük serbest zaman süresini yeterli görürken, 109’u (\%49.3) yeterli görmemektedir. Ayrıca, katıllımcıların 111’i (\%50.2) düzeli olarak herhangi bir etkinliğe katulırken, 110’u (\%49.8) katılmamaktadır. Bununla beraber, kattlımcıların kurumda görev alma süresinin ortalaması ise $4.31 \pm 4.80$ yll olarak tespit edilmiştir.

\section{Veri Toplama Araçları}

Araştırmada veri toplama aşamasında kişisel bilgi formunun yanı sıra "İşs-Serbest Zaman Çatışma Ölçeğì” ile "Algılanan Örgütsel Destek Ölçeği” kullanılmıştır. 
Kurtipek, S., Ayyıldız Durhan, T., \& Güngör, N. B. (2021). İș serbest zaman çatışmasında algılanan örgütsel desteğin rolü. Journal of Human Sciences, 18(4), 715-727. doi:10.14687/jhs.v18i4.6235

\section{İs-Serbest Zaman Çatısma Ölçeği}

Wong \& Lin (2007) tarafindan geliştirilen ölçek 5 maddeden oluşmaktadır. Ölçeğin Türkçe uyarlamasını Sop (2014) yılında gerçekleştirmiştir. Ölçekte yer alan ifadeler "tamamen katılmıyorum" ve "tamamen katılıyorum" ifadeleri aralığında 7'li bir derecelendirmeye sahiptir. Ölçekte alınabilecek puanın yüksekliği çatışma düzeyinin arttığını işaret etmektedir. Ayrıca, veri setinden elde edilen iç tutarlık katsayısı .95 olarak tespit edilmiştir.

\section{Algilanan Örö̈tsel Destek. Ölçeği}

Eisenberger ve ark. (1997)'nın geliştirdiği ölçek Kanbur (2015) tarafindan geçerlik güvenirliği gerçekleştirilerek dilimize kazandırılmıştır. Ölçek toplamda 8 maddeden oluşmaktadır ve 2 madde ters puanlanmaktadır. "Kesinlikle katılmıyorum" ve "Kesinlikle katılıyorum" ifadeleri aralığında 5'li likert bir yapıdadır. Bununla beraber, veri setinden elde edilen iç tutarlık katsayısı .90’dır.

\section{Verileri Analizi}

Verilerin analizine ilk olarak veri setinde yer alan uç değerlerin tespiti ile başlanmıştır. Bu kapsamda, 8 veri formu araştırma dışında yer almıştır. Ayrıca, Kolmogorov Smirnov ve Shapiro-Wilk testleri anlamlılı sonucuna bakılarak çarpıklık ve basıklık değerleri dikkate alınmıştır. Araştırmada kullanılan ölçme araçları için bu değerler -1.5 ile +1.5 arasındadır (ISZÇÖ= .22, -.70; AÖDÖ= -.12, -.72). Elde edilen bu sonuçlar verilerin normal dağılım şartlarını karşıladığını ifade etmektedir (Tabachnick \& Fidell, 2013). Ölçeklerden elde edilen toplam puanların cinsiyet, düzenli etkinlik kattlımı, günlük serbest zaman süresinin yeterli görülme değişkenleri ile karşılaştırılmasında T-testi; ölçeklerden elde edilen puanların belirlenmesinde betimsel istatistikler, değisskenler arasındaki ilişkinin belirlenebilmesi için Pearson Momentler Çarpımı Korelasyonu Testi ve Regresyon Analizi araştırma kullanılmıştır. İlgili analizler SPSS 22 Paket Programı ve Excel Veri Tabanı kullanılarak gerçekleştirilmiştir.

\section{BULGULAR}

Tablo 1. Katılımcıların İş-Serbest Zaman Çatışması Ölçeği ve Algılanan Örgütsel Destek Ölçeğinden Aldıkları Ortalama Puanlar

\begin{tabular}{llllll}
\hline Ölçekler & N & Min & Max & $\overline{\mathbf{x}}$ & S \\
\hline İş-Serbest Zaman Çatışması & 221 & 1.00 & 7.00 & 3.87 & 1.64 \\
\hline Algıllanan Örgütsel Destek & 221 & 1.00 & 5.00 & 3.44 & .96 \\
\hline
\end{tabular}

Katıllımcıların İş-Serbest Zaman Çatşması Ölçeğinden aldıkları ortalama puan ( $\bar{x}=3.87)$, Algılanan Örgütsel Destek Ölçeğinden ise $(\bar{x}=3.44)$ olarak tespit edilmiştir.

Tablo 2. Katılımcıların Ölçeklerden Aldıkları Puan Ortalamalarının Cinsiyet Değişkenine Göre Ttesti Sonuçları

\begin{tabular}{llllllll}
\hline & Cinsiyet & $\mathbf{N}$ & $\overline{\mathbf{x}}$ & $\mathbf{S s}$ & $\mathbf{s d}$ & $\mathbf{t}$ & $\mathbf{p}$ \\
\hline \multirow{\text{ISZC}}{*}{} & Erkek & 140 & 3.81 & .15 & 219 & -.747 & .46 \\
\cline { 2 - 6 } & Kadın & 81 & 3.98 & .16 & & & \\
\hline \multirow{2}{*}{ AÖD } & Erkek & 140 & 3.47 & .08 & \multirow{2}{*}{219} & .681 & .50 \\
\cline { 2 - 5 } & Kadın & 81 & 3.38 & .09 & & & \\
\hline
\end{tabular}

İSZÇ: İş-Serbest Zaman Çatışması, AÖD: Alg1lanan Örgütsel Destek

Kadın katılımcıların İş-Serbest Zaman Çatışması Ölçeğinden aldıkları ortalama puan $(\bar{x}=3.98)$, erkek katılımcıların $(\bar{x}=3.81)^{\prime}$ dir. Bununla beraber; kadın katılımcıların Alg1lanan Örgütsel Destek Ölçeğinden aldıkları ortalama puan $(\bar{x}=3.38)$, erkek katılımcıların ise $(\bar{x}=3.47)$ 'dir. Analiz sonuçları incelendiğinde; katılımcıların iş-serbest zaman çatışması ve algılanan örgütsel destek 
Kurtipek, S., Ayyıldız Durhan, T., \& Güngör, N. B. (2021). İş serbest zaman çatışmasında algılanan örgütsel desteğin rolü. Journal of Human Sciences, 18(4), 715-727. doi:10.14687/jhs.v18i4.6235

düzeylerinin cinsiyete göre istatistiksel olarak farklılaşmadığ1 sonucuna ulaşılmıştır, $\mathrm{t}_{1}(219)=-.747$, $\mathrm{p}>.05 ; \mathrm{t}_{2}(219)=.681, \mathrm{p}>.05$.

Tablo 3. Katılımcıların Ölçeklerden Aldıkları Puan Ortalamalarının Günlük Serbest Zaman Süresinin Yeterli Görülme Değişkenine Göre T-testi Sonuçları

\begin{tabular}{llllllll}
\hline & Durum & $\mathbf{N}$ & $\overline{\mathbf{x}}$ & $\mathbf{S s}$ & $\mathbf{s d}$ & $\mathbf{t}$ & $\mathbf{p}$ \\
\hline \multirow{\text{ISSZC}}{*}{} & Evet & 112 & 3.03 & .12 & 219 & -8.99 & .00 \\
\cline { 2 - 7 } & Hayır & 109 & 4.73 & .14 & & & \\
\hline AÖD & Evet & 112 & 3.62 & .08 & \multirow{2}{*}{219} & 3.03 & .00 \\
\cline { 2 - 7 } & Haylr & 109 & 3.24 & .09 & & & \\
\hline
\end{tabular}

İSZÇ: İş-Serbest Zaman Çatışması, AÖD: Alg1lanan Örgütsel Destek

Katılımcıların iş-serbest zaman çatışmalarının günlük serbest zaman süresinin yeterli görülme durumuna göre ilgili süreyi yeterli görenlerin lehine istatistiksel olarak farklllaştığ1 sonucuna ulaşılmıştır, $\mathrm{t}_{1}(219)=-8.99, \mathrm{p}<.05$. Buna ek olarak; katılımcıların algılanan örgütsel destek düzeyinin günlük serbest zaman süresinin yeterli görülme durumuna göre ilgili süreyi yeterli görenlerin lehine anlamlı bir şekilde farklılaştı̆̆ ifade edilebilir, $\mathrm{t}_{2}(219)=3.03, \mathrm{p}<.05$.

Tablo 4. Katılımcıların Ölçeklerden Aldıkları Puan Ortalamalarının Düzenli Etkinlik Katılımı Değişkenine Göre T-testi Sonuçlanı

\begin{tabular}{llllllll}
\hline & Durum & $\mathbf{N}$ & $\overline{\mathbf{x}}$ & $\mathbf{S s}$ & $\mathbf{s d}$ & $\mathbf{t}$ & $\mathbf{p}$ \\
\hline ISZÇ & Evet & 111 & 3.54 & .15 & 219 & -3.06 & .002 \\
& Hayır & 110 & 4.20 & .16 & & & \\
\hline AÖD & Evet & 111 & 3.52 & .09 & \multirow{2}{*}{219} & 1.308 & .192 \\
\cline { 2 - 7 } & Hayır & 110 & 3.35 & .08 & & & \\
\hline
\end{tabular}

İSZÇ: İş-Serbest Zaman Çatışması, AÖD: Algılanan Örgütsel Destek

İş-Serbest Zaman Çatışması Ölçeğinden katılımcıların almış oldukları ortalama puan düzenli etkinlik katılımı değişkenine göre karşılaştırıldığında, düzenli etkinliğe katılım göstermeyen bireylerin aldıklan puan ortalamasının istatistiksel daha yüksek olduğu sonucuna ulaşılmıştır, $t_{1}(219)=-3.06$, p>.05. Ayrıca katıllımcıların Algılanan Örgütsel Destek Ölçeğinden elde etmiş oldukları ortalama puan ile düzenli etkinlik katılımı değişkeni karşılaştırıldığında anlamlı bir farklılığın olmadığı belirlenmiştir, $\mathrm{t}_{2}(219)=1.308, \mathrm{p}>.05$.

Tablo 5. Değişkenler Arası İlişkinin Pearson Momentler Çarpımı Korelasyonu ile İncelenmesi

\begin{tabular}{ll}
\hline Değişken & Alg1lanan Örgütsel Destek \\
\hline İş-Serbest Zaman Çatışması & -.231 \\
\hline$* * \mathrm{p}<.01$ &
\end{tabular}

Tablo 5 dikkate alındığında, katılımcıların İş-Serbest Zaman Çatışması Ölçeği ile Algılanan Örgütsel Destek Ölçeğinden elde ettikleri puanlar arasında negatif yönlü ve düşük düzeyde bir ilişkinin olduğu ifade edilebilir, $\left(\mathrm{r}_{1}=-.231, \mathrm{p}<.01\right)$. Bu noktadan hareketle, iş-serbest zaman çatışması arttıkça algılanan örgütsel desteğin düştüğü ifade edilebilir.

Tablo 6. İş Serbest Zaman Çatışmasının Yordanmasına İlişkin Regresyon Analizi Sonuçları

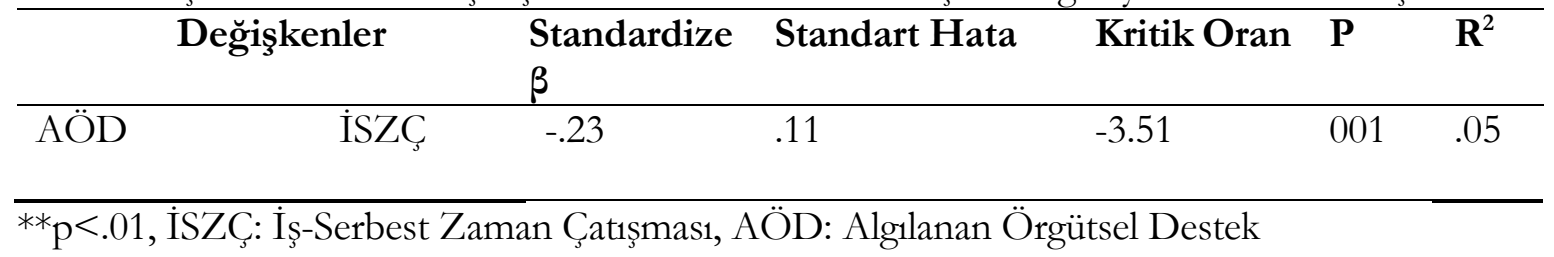


Kurtipek, S., Ayyıldız Durhan, T., \& Güngör, N. B. (2021). İș serbest zaman çatışmasında algılanan örgütsel desteğin rolü. Journal of Human Sciences, 18(4), 715-727. doi:10.14687/jhs.v18i4.6235

Analiz sonuçları incelendiğinde, iş-serbest zaman çatışması ile algılanan örgütsel destek arasında istatistiksel olarak anlamlı bir etki belirlenmiştir, $\left(\beta_{1}=-.23 ; \mathrm{p}<.001\right)$. Ayrıca; Squared Multiple Correlations $\left(\mathrm{R}^{2}\right)$ değeri dikkate alındığında, -serbest zaman çatışmasının \%05'inin algılanan örgütsel destek ile açıllandığı söylenebilir.

\section{TARTIŞMA VE SONUÇ}

İş serbest zaman çatışmasında algıllanan örgütsel desteğin rolünün Gençlik ve Spor Bakanlığ1 personeli üzerinde incelendiği araştırma bulguları; katılımcıların ortalama düzeyde iş serbest zaman çatışması yaşadığını ancak örgütlerinden algıladıkları destek düzeylerinin ortalamanın üzerinde olduğu belirlenmiştir. Dolayısıyla bulgular katılımcıların iş ve serbest zaman arasında çatışma yaşadığını ancak örgütsel bağlamda sosyal destek aldığını ortaya koymaktadır. Bir diğer bulgu Sop’un (2014) araştırmasında elde edilmiş, turizm çalışanları üzerinde yapılan araştırmada düşük düzeyde iş-serbest zaman çatışması yaşandığı belirlenmiştir. Bir diğer araştırma ise mevcut bulguyla paralel biçimde otel çalışanlarının iş ve serbest zaman çatışma düzeylerinin orta düzeyde olduğunu göstermektedir (İskender ve Yayl1, 2017). Lin, Wong \& Ho (2015) ve Zhao (2010) düşük iş yükünün iş serbest zaman çatışmasını azaltmada etken olduğu ifade etmektedir.

İş yükü kaynağı örgüt sistemleri olması sebebiyle işgörene verilecek iş yükündeki esneklik gibi firsatlar işgörenin iş ve serbest zaman arasındaki dengeyi kurmasına katkı sağlayan bir faktör olacaktır. Bu bağlamda mesai saatlerinin 48 saatin üzerinde tutulmaması ve işten arta kalan serbest zamanlarda işgörenin yapması üzere ek iş verilmemesi alg1lanan örgütsel desteği de olumlu etkileyecek unsurlar arasindadir.

Yapılan araştırmalar çalışanların iş yüklerinin isteklerinin üzerinde olduğunu gösterir niteliktedir. Bu çalışmalardan biri olan Wang ve diğerlerinin 2020 yllında yaptıkları araştırmada otel çaışanlarının görüşleri alınmış ve otel çalışanları çalışma koşullarının serbest zaman değerlendirmek için çok az firsat tanıdığını belirtmişlerdir. Katılımcıların serbest zaman aktivitelerinden zevk almasına ve iş stresinden kurtulmak için serbest zamana ihtiyaç duymasına rağmen, uzun çalışma saatlerinin serbest zamanlarından kaynak kazanmayı zorlaştırdığı yönündeki görüşleri araştırma bulgularının önemli yönünü oluşturmaktadır.

Literatür incelendiğinde iş yükünün iş-serbest zaman çatışması ile pozitif bir ilişkisi olduğu, ancak iş koşullarındaki esnekliğin işten-serbest zaman çatışması ile negatif ilişkili olduğu saptanmıştır (Lin, Wong ve Ho, 2013). İş serbest zaman çatışmasının iş stresini ve tükenmişliği artırdığı belirlenmiştir (Mansour \& Mohanna, 2017; Lin ve diğ, 2014; Meier ve diğ., 2021; Tepavčević, 2019). İlgili bulgu iş verimi düşürmede iş serbest zaman çatışmasının etken olabileceği yönünde kanaat oluşturmaktadır. Bir diğer çalışmada iş serbest zaman arasında gerçekleşen esnek durumun iş yeterliliği üzerinde önemli derecede olumlu etkileri olduğunu göstermiştir (Liang, 2020). Dolayısıyla esneklik gibi kişisel kaynakların daha fazla iş serbest zaman dengesi ortaya koyabileceği ifade edilebilir (Wayne ve diğ., 2020). İş saatlerindeki ve iş yükündeki katı prensipler yerine işgörenlerin çeşitli özgürlükler çerçevesinde sınırlandırılması iş serbest zaman çatışması durumlarını olumlu etkileyecek unsurlar arasında gösterilebilir.

Çalışanları destekleyen, iş serbest zaman dengelerini kurmayı hedefleyen benzeri uygulamalar ile çalışanlar kendilerine yatırım yapıldığı, önem verildiğini hissederek örgütsel destek algılarını olumlu biçimde artıracaktır. Örgütsel destek algısı yükselen çalışanların kurumlarında gayretli çalışması ile, motivasyonlarının artması sağlanarak ve dolaylı olarak da kurumlannda daha verimli olmaları söz konusu olacaktır. Bu denklemde algılanan örgütsel desteğin azalması da çeşitli problemlere yol açabilir varsayımı doğrulanmaktadır (Aykan, 2007).

Araştırma bulguları iş serbest zaman çatışmasının ve algılanan örgütsel desteğin cinsiyet değişkenine göre farklılık göstermediğini ortaya koymaktadır. Bir diğer araştırmada ise erkeklerin kadınlara oranla daha fazla iş-serbest zaman çatışması yaşadığı belirtilmiştir (Staines \& O'Connor, 1980). Aynı zamanda algılanan örgütsel destekte de yine cinsiyete göre farklılık saptanmadığ1 mevcut araştırmayla ve çeşitli araştırmalarla ortaya koyulmuştur (Kartal, Yirci ve Özdemir, 2015). İş hayatında kadın ve erkeklerin eşit fırsatlarla iş gücüne katılabildiği spor örgütlenmeleri kadınların yaşadığ1 
Kurtipek, S., Ayyıldız Durhan, T., \& Güngör, N. B. (2021). İş serbest zaman çatışmasında algılanan örgütsel desteğin rolü. Journal of Human Sciences, 18(4), 715-727. doi:10.14687/jhs.v18i4.6235

dezavantajlanı ortadan kaldırma noktasında katkı sağlamıştır. Bu bağlamda kadın ve erkeklerin benzeş iş yükü ile çalıștı̆̆ Gençlik ve Spor Bakanlığ1 personelinin iş-serbest zaman çatısması ve algılanan örgütsel destek düzeyi sergilemelerinde farklılık yaşanmaması personelin eşitlikçi çalışma koşullarına bağlanabilir.

Yapılan bir başka araşturmada çalışanların serbest zamana yönelik sosyal fayda sağlaması sürecinden oldukça memnuniyet duyduğu, bu durumun dolaylı olarak işten-serbest zaman çatısması ile yaşam kalitesi arasında 1 lımlı bir etki yarattı̆ı görülmektedir. Serbest zaman sosyal yardım sisteminin, cephe çalışanlarının işten-serbest zaman çatsşması için başa çıkma kaynağı olduğunu göstermektedir (Lin, Wong\&Ho, 2013).

Katılımcıların iş-serbest zaman çatışmalarının günlük serbest zaman süresinin yeterli görülme durumuna göre ilgili süreyi yeterli görenlerin lehine istatistiksel olarak farklılaştığ1 sonucuna ulaşılmıştır. Dolayısıyla günlük serbest zaman süresini yeterli görme durumunun algıllanan örgütsel desteği artırdığı, diğger yandan iş serbest zaman çatışmasını azalttığı ifade edilebilir. Buna paralel olarak Ankara'da ye otel çalışanlarının iş-serbest zaman çatışma düzeyleri diğer parametreleri inceleyen araştırmada mesai saatlerindeki artışın otel çalışanları iş serbest zaman çatışma düzeyini artırdığını göstermektedir (İskender ve Yayll, 2017). Elde edilen bulgular literatürde de yer aldığ1 üzere mesai saatlerindeki artışın, serbest zaman kaynaklarını sınırlandırdığı ve iş serbest zaman çatışmasının önünü açtığını gösterir niteliktedir.

ISZÇ ve AÖD arasında negatif yönlü ve düşük düzeyde bir ilişkinin olduğu ve $\left(\mathrm{r}_{1}=-.231, \mathrm{p}<.01\right)$. AÖD'nin İSZÇ'yi etkilediği belirlenmiştir. Bir diğer araştırmada iş-serbest zaman çatışması ve mesleki tükenmişlik ve yaşam tatmin düzeyleri arasında istatistiksel açıdan anlamlı olarak orta ve düşük düzeyli ilişkiler belirlenmiştir (İskender ve Yayl1, 2017). Literatür bulguları değerlendirildiğinde alg1lanan örgütsel destek ve örgütsel davranış ile pek çok psikososyal parametrenin anlamlı ilişkiler ortaya koyduğu (Akkoç, Çalışan ve Turunç, 2012; Eisenberger ve diğ., 2001; Kaçay, Güngör, Yenel ve Soyer, 2020; Meriç, Öztürk Çiftci ve Yurtal, 2019; Ötken, 2015; Karaalioğlu, 2019; Koçak ve Yücel, 2018; Kurtosis ve diğ, 2017; Muneer ve diğ., 2014; Özdemir, 2010; Özdemir, Özcan ve Yalçınkaya, 2019). Turunç ve Çelik, 2010; Uzun, 2018) belirlenmiştir.

Kuruluşlar, çalışan hedefleriyle ilintili olarak çalışanların ilgi alanlarını takip etmek, spor salonlarının yardımıyla hobiler, sağlık kulübü, kitap kulübü, macera kulübü, dans kulübü, sosyal toplantılar gibi çalışmalar yaptığı takdirde bir organizasyon amaçlarından ziyade çalışanların refahını düşünür pozisyon alabilir (Sharma \& Nambudiri, 2015). İş-serbest zaman çatışması refahı olumsuz etkileyebileceğinden, çalışanlar sinemaya gitmek, dağa tırmanmak, bahçe işleri, bilgi teknolojisi sergisi, flört, fotoğrafçılık ve benzeri etkinliklere katılarak serbest zamanlarını verimli değerlendirme yollarını öğrenebilir ve serbest zaman değerlendirme alışkanlıkları kazanabilirler. Böylelikle çalışanlar yalnızca serbest zamanlarına geçiş kapısı geliştirmekle kalmaz, aynı zamanda yaşam ve duygusal tatmin üzerinde olumlu bir etkiye sahip olan iş yerinde enerji ve ortak hedefler edinirler (Lin ve diğ., 2013). İşverenlerin çeşitli departmanları aracilığıyla serbest zaman aktiviteleri yapmak için serbest zaman planlamaları yapması gerektiği, iş serbest zaman dengesi için çeşitli grup çalışmaları uygulanabileceği ve bunların yanı sıra iş serbest zaman dengesinin önemini vurgulayacak seminerler vermesi gerektiği söylenebilir.

Sonuç olarak alg1lanan örgütsel desteğin iş serbest zaman çatışmasını azaltacağı söylenebilir. Örgütlerin çalışan verimliliğini artırmak, hizmet kalitesini olumlu yöne çekebilmek ve çalışanların psikososyal olarak iyileşmelerinin önünü açmak için örgütlerden gördükleri desteklerin iş serbest zaman dengesini kurmaya yardımcı biçimde tasarlanması gerektiği düşünülmektedir. Bu doğrultuda örgütlerin politikalarına çalışanların iş serbest zaman çatışmasını azaltmaya yardımcı unsurlar eklemeleri ve gelecek politikaları bu bağlamda yapılandırmaları öneriler arasındadır. Aynı zamanda farklı çalışma gruplarıyla yapılacak iş serbest zaman çatışması ve algılanan örgütsel destek araştırmalarıly alanın genişletilmesi önerilmektedir. 
Kurtipek, S., Ayyıldız Durhan, T., \& Güngör, N. B. (2021). Isş serbest zaman çatışmasında algılanan örgütsel desteğin rolü. Journal of Human Sciences, 18(4), 715-727. doi:10.14687/jhs.v18i4.6235

\section{KAYNAKLAR}

Afacan Fındıklı, M. (2014). Algılanan Lider Desteği ve Algılanan Örgütsel Destek İle İşten Ayrilma Niyeti İlişkisinde Örgütsel Özdeşlemenin Aracılık Rolü: İstanbul'da Kamu Çalışanları Üzerine Bir Araştırma. İ. Ü. İsletme Fakültesi İsletme İktisadı Enstitüsü Yönetim Dergisi, 25(77), 136-157.

Akgündüz, Y., Çakıcı, C. (2015). Algılanan Örgütsel Desteğin Örgütsel Vatandaşlık Davranışlarına Etkisinde Örgütsel Stresin Aracılık Rolü: Beş Yıldızlı Otel İşletmelerinde Bir Araştırma. Uluslararasi Alanya Isletme Fakïltesi Dergisi, 7(2), 29-41.

Akkoç, İ., Çalışkan, A., Turunç, Ö. (2012). Örgütlerde Gelişim Kültürü ve Algılanan Örgütsel Desteğin İş Tatmini ve İss Performansina Etkisi: Güvenin Aracılık Rolü. Yönetim ve Ekonomi, 19(1), 105-135.

Aykan, E. (2007). Örgütlerde İnsan Kaynakları Uygulamaları ile Alg1lanan Örgütsel Destek Arasındaki İlişkilerin Belirlenmesine Yönelik Bir Araştırma. Dokuz Eylül Üniversitesi İktisadi ve İdari Bilimler Fakïltesi, 22 (1), 123-137.

Büyükgöze, H., Kavak, Y. (2017). Alg1lanan Örgütsel Destek ve Pozitif Psikolojik Sermaye İlişkisi: Lise Öğretmenleri Örnekleminde Bir İnceleme. Kuram ve Uygulamada Eğitim Yönetimi, 23(1), 1 32.

Büyükyılmaz, O., Çakmak, A. F. (2014). İlişkisel ve İşlemsel Psikolojik Sözleşmede Algılanan İhlalin İșten Ayrılma Niyeti ve Algılanan Örgütsel Destek Üzerindeki Etkisi. Ege Akademik Bakış, 14(2),583-596.

Eisenberger, R., Armeli, S., Rexwinkel, B., Lynch, P.D., Rhoades, L. (2001). Reciprocation of Perceived Organizational Support. Journal of Applied Psychology, 86(1), 42-51

Eisenberger, R., Cummings, J., Armeli, S. \& Lynch, P. (1997). Perceived Organizational Support, Discretionary Treatment, and Job Satisfaction. Journal of Applied Psychology, 82(5), 812-820.

Eisenberger, S., Huntingdon, R., Hutchinson, S., \& Sowa, D. (1986). Perceived organizational support. Journal of Applied Psychology, 71(3), 500-507.

Erkoç, İ.Ç. (2015). Algilanan Örgütsel Destek ve İș Performansı Arasındaki İlişkide Öz Yeterlilik Faktörünün Dürenleyici Rolü: Bankacllke Sektöründe Bir Arastorma. İstanbul Kültür Üniversitesi, Sosyal Bilimler Enstitüsü. Yüksek Lisans Tezi, İstanbul.

Guest, D.E. (2001). Perspectives on the Study of Work-Life Balance. A Discussion Papared fort he 2001 ENOP Symposium, Paris.

Güney, S., Akalın, Ç., İlsev, A. (2007). Duygusal örgütsel bağlllık gelişiminde algylanan örgütsel destek ve örgüt temelli öz-sayg1. H.Ü. İktisadi ve İdari Bilimler Fakültesi Dergisi, 25(2), 189-211.

İskender, A., Yaylı, A. (2017). İşgörenlerin iş ve serbest zaman çatışma düzeyleri ile mesleki tükenmişlik ve yaşam tatmini ilişkisi: Ankara'daki 4-5 yıldızlı otel çalşanları üzerine bir uygulama. Manas Sosyal Arastırmalar Dergisi, 6(1), 95-112.

Jun, J., Kyle, G.T. (2011). The Effect of Identity Conflict/Facilitation on the Experience of Constraints to Leisure and Constraint Negotiation. Journal of Leisure Research,43(2), 176-204.

Kaçay, Z., Güngör, N.B., Yenel, F., Soyer, F. (2020). The effect of work engagement and mindfulness on organizational behavior, Journal of Educational Issues, 6(2), 478-492

Kanbur, E. (2015). Çalısanlarn bireysel yaratıchlk düzeyinin ic girişimcilik performanslarn üzerindeki etkisinde alglanan örgütsel desteğin aracılı. rolü. Doktora tezi. Gaziosmanpaşa Üniversitesi Sosyal Bilimler Enstitüsü, Tokat.

Karaalioğlu, Z. F. (2019). Algzlanan Örgütsel Destek İle Ișs Performansı İlişkisinde Örgütsel Özdeşlesme, Iss Tatmini Ve Örgütsel Vatandaşlık Davramısımn Aracı Rolü. İstanbul Ticaret Üniversitesi Sosyal Bilimler Enstitüsü, Doktora Tezi, İstanbul.

Karasar, N. (2013). Bilimsel Araştırma Yöntemi. Ankara: Nobel Yayınevi.

Kartal, S. E., Yirci, R., Özdemir, T. Y. (2015). Öğretmenlerde Alg1lanan Örgütsel Destek Düzeyi İle Yaşam Memnuniyeti Arasındaki İlişkinin İncelenmesi. Dicle Üniversitesi Ziya Gökalp Eğitim Fakültesi Dergisi, 24,477-504. 
Kurtipek, S., Ayyıldız Durhan, T., \& Güngör, N. B. (2021). İş serbest zaman çatışmasında algılanan örgütsel desteğin rolü. Journal of Human Sciences, 18(4), 715-727. doi:10.14687/jhs.v18i4.6235

Kerse, G., Karabey, C. N.(2017). Algilanan örgütsel desteğin örgütsel özdeşleşmeye etkisi: örgütsel sinizmin arac1 rolü. MANAS Sosyal Arastırmalar Dergisi, 6(4), 375-398.

Koçak, D., Yücel, İ. (2018). Alg1lanan Örgütsel Destek İle İşten Ayrllma Niyeti Arasındaki İlişkide Duygusal Bağlllı̆̆ın Aracı Etkisinin İncelenmesi. Atatürk Üniversitesi İktisadi ve İdari Bilimler Dergisi, 32 (3), 683-704.

Kurtosis, J.N., Eisenberger, R., Ford, M.T., Buffardi, L.C., Stewart, K.A., Adis, C.S. (2017). Perceived Organizational Support: A Meta-Analytic Evaluation of Organizational Support Theory. Journal of Management, 43(6), 1854-1884.DOI: 10.1177/0149206315575554

Liang, Y.W. (2020) Consequences of work-leisure facilitation from tour leaders'/guides' perspectives: Self-efficacy and satisfaction, Journal of Leisure Research, 51(2), 206-229, DOI: 10.1080/00222216.2019.1670586.

Lin, J.H., Wong, J.Y., Ho, C.H. (2013). Beyond the Work-to-Leisure Conflict: A High Road through Social Support for Tourism Employees. International Journal of Tourism Research, Int. J. Tourism Res., 16, 614-624. DOI: 10.1002/jtr.1956

Lin, J.H., Wong, J.Y., Ho, C.H. (2013). Promoting frontline employees' quality of life: Leisure benefit systems and work-to-leisure conflicts. Tourism Management, 36, 178-187.

Lin, J.H., Wong, J.Y., Ho, C.H. (2015). The role of work-to-leisure conflict in promoting frontline employees' leisure satisfaction Examining the job demand-control-support model. International Journal of Contemporary Hospitality Management, 27, 7, 1539-1555.

Lin, Y.S., Chang, S.H., Chang, L.H., Yeh, C.S. (2013). The relationships between work-leisure conflict and well-being: the roles of leisure participation and job burnout. International Journal of Asian Tourism Management, 4 (2), 126-136.

Lin, Y.S., Huang, W.S., Yang, C.T., Chiang, M.J. (2013). Work-leisure conflict and its associations with well-being: The roles of social support, leisure participation and job burnout. Tourism Management, 45, 244-252.

Mansour, S., Mohanna, D. (2018). Mediating role of job stress between work-family conflict, workleisure conflict, and employees' perception of service quality in the hotel industry in France. Journal of Human Resources In Hospitality \& Tourism, 17(2), 154-174 https://doi.org/10.1080/15332845.2017.1340755

Mansour, S., Tremblay, D.G. (2016). How the need for "leisure benefit systems" as a "resource passageways" moderates the effect of work-leisure conflict on job burnout and intention to leave: A study in the hotel industry in Quebec. Journal of Hospitality and Tourism Management, 27, 4-11.

Meier, E., Aziz, S., Wuensch, K., Dolbier, C. (2021). Work hard, play hard or maybe not: A look at the relationships between workaholism, work-leisure conflict, and work stress. Journal of Leisure Research, 52(3) 330-346 https://doi.org/10.1080/00222216.2020.1778589

Meriç, E., Öztürk Çiftci, D., \& Yurtal, F. (2019). Algılanan örgütsel destek ve işe adanmışlık arasındaki ilişkinin incelenmesi. Kastamonu Education Journal, 27(1), 65-74. doi:10.24106/kefdergi.2296

Muneer, S., Javed Iqbal, S.M., Khan, S.R., Long, C.S. (2014). An Incorporated Structure of Perceived Organizational Support, Knowledge-Sharing Behavior, Organizational Trust and Organizational Commitment: A Strategic Knowledge Management Approach. Pakistan Journal of Commerce and Social Sciences, 8 (1), 42- 57.

Ötken, A.B. (2015). Alg1lanan Örgütsel Destek ve Psikolojik Sahiplenme Arasındaki İlişki Ve Bu İlişkide Örgütsel Adaletin Rolü. Hacettepe Üniversitesi İktisadi ve İdari Bilimler Fakülttesi Dergisi, 33(2), 113-140.

Özdemir, A. (2010). Örgütsel Özdeşleşmenin Alg1lanan Örgütsel Destek, Cinsiyet ve Kıdem Değişkenlerine Göre İncelenmesi. Türkiye Sosyal Arasstirmalar Dergisi, 14(1), 237-250.

Özdemir, B., Özcan, H.M., Yalçınkaya, A. (2019). Algılanan Örgütsel Destek ve Çalışmaya Tutkunluk Arasındaki İlişkide Örgütsel Güvenin Aracı Rolü: Akademisyenler Üzerine Bir Araştırma. Bilecik Şeyh Edebali Üniversitesi Sosyal Bilimler Enstitïsï Dergisi, 4(2), 706-724. DOİ: 10.33905/bseusbed.640815 
Kurtipek, S., Ayyıldız Durhan, T., \& Güngör, N. B. (2021). İş serbest zaman çatışmasında algılanan örgütsel desteğin rolü. Journal of Human Sciences, 18(4), 715-727. doi:10.14687/jhs.v18i4.6235

Özdevecioğlu, M. (2003). Algılanan örgütsel destek ile örgütsel bağlllkk arasındaki ilişkilerin belirlenmesine yönelik bir araşturma. D.E.Ü.İ.I.B.F. Dergisi, 18 (2), 113-130.

Özdevecioğlu, M., Çakmak Doruk, N. (2009). Organizasyonlarda iş-aile ve aile iş çatışmalarının iş ve yaşam tatminleri üzerindeki etkisi. Erciyes Üniversitesi İktisadi ve İdari Bilimler Fakë̈ltesi Dergisi, 33, 69-99.

Parasız, Ö., Koç, M., Ilgar, E., \& Şahin, M. Y. (2017). Relationship between organizational commitment and turnover intentions of academics. Journal of Human Sciences, 14(4), 40654076.

Sharma, A., Nambudiri, R. (2015). Job-Leisure Conflict, Turnover Intention and the Role of Job Satisfaction as a Mediator: An Empirical Study of Indian IT Professionals. South Asian Journal of Management, 22(1), 7-27.

Shi, W., Wang, F., Li, X. (2021) Depletion Efect of Work-Leisure Confict: A Daily Diary Study. Social Indicators Research https://doi.org/10.1007/s11205-021-02710-x

Sop, S.A. (2014). İş Baskısı, İş-Serbest Zaman Çatışması, Meslek Memnuniyeti ve Yaşam Doyumu İlişkisi Üzerine Bir İnceleme. Turiz̧ Akademik Dergisi, 1 (1), 1-14.

Staines, G.L., O'Connor, P. (1980). Conflicts among work, leisure, and family roles. Monthly Labor Review, 103(8), 35-39.

Tabachnick, B. G., \& Fidell, L. S. (2013). Using multivariate statistics: International edition. Pearson 2012.

Tamer, İ., Bozaykut Bük, T. (2020). Alg1lanan örgütsel destek ve örgütsel bağlllik üzerine kavramsal bir inceleme. Avrasya Sosyal ve Ekonomi Araştırmalar Dergisi (ASEAD), 7 (2), 139-147.

Tanriverdi, H., Kılıç, N. (2016). Algılanan Örgütsel Destek ve Örgütsel Yabancilaşma Arasındaki İlişkinin İncelenmesi. Hacettepe Üniversitesi, Sosyolojik. Araștrmalar E-Dergisi, 1(1), 1-18.

Tepavčević, J., Vukosav, S., Mijatov, M., Bradić, M., Garača, V. (2019). Determining the Relations between Work-Leisure Conflict, Leisure Participation, Job Burnout and Overall Life Satisfaction. International Conference on Administration Management and Social Studies, 13 - 14 September 2019 Bosnia and Herzegovina / Sarajevo

Tsaur, S.H., Liang, Y.W., Hsu., H.J. (2012). A Multidimensional Measurement of Work-Leisure Conflict. Leisure Sciences, 34: 395-416.

Turunç, Ö., Çelik, M. (2010). Çalışanların Algıladıkları Örgütsel Destek ve İş Stresinin Örgütsel Özdeşleşme ve İş Performansına Etkisi. Yönetim ve Ekonomi, 17(2), 183-206.

Uğur O. A, \& Yenel F. (2007). Beden eğitimi öğretmenlerinin sınıf yönetimi yaklaşımları ve karşılaştıkları sorunlar üzerine bir araştırma. Türkiye Sosyal Araştırmalar Dergisi, 11(1), 149173.

Uğur, O. A. \& Güngör, N. B. (2021). The effect of time management on the prediction of the personal growth initiatives of the students of the faculty of sports sciences, International Journal of Eurasian Education and Culture, 6(14), 1714-1741.

Uzun, T. (2018). Okullarda alg1lanan örgütsel destek, örgütsel güven, duygusal bağlllik ve örgütsel vatandaşlık davranışı arasındaki ilişkiler. OPUS -Uluslararası Toplum Araştırmalarn Dergisi, 8(15), 958-987. https://doi.org/10.26466/opus.418335.

Üren, S.G., Çorbacioğlu, S. (2012). Alg1lanan Örgütsel Desteğin Örgütsel Bağlllı̆̆a Etkisi: İmalat Sektöründe Faaliyet Gösteren Bir İşletme Örneği. Gaži Üniversitesi İktisadi ve İdari Bilimler Fakültesi Dergisi, 14(1), 29-52.

Wang, F., Shi, W. (2020). The effect of work-leisure conflict on front-line employees' work engagement: A cross-level study from the emotional perspective. Asia Pacific Journal of Management https://doi.org/10.1007/s10490-020-09722-0

Wang, Y.C., Qu, H., Yang, Y., Yang, C.E. (2020). Leisure-work preference and hotel employees' perceived subjective well-being. The Service Industries Journal, 40 (1-2), 110-132.

Wayne, J.H., Matthews, R., Crowford, W., Casper, W.J. (2020). Predictors and processes of satisfaction with work-family balance: Examining the role of personal, work, and family resources and conflict and enrichment. Human Resource Management, 59, 25-42. 
Kurtipek, S., Ayyıldız Durhan, T., \& Güngör, N. B. (2021). İş serbest zaman çatışmasında algılanan örgütsel desteğin rolü. Journal of Human Sciences, 18(4), 715-727. doi:10.14687/jhs.v18i4.6235

Wong, J.Y., Lin, J.H. (2007). The role of job control and job support in adjusting service employee's work-to-leisure conflict. Tourism Management, 28, 726-735.

Zhao, L. (2010). The mediating role of work-leisure conflict on job stress and retention of it professionals. Academy of Information and Management Sciences Journal, 13(2),25-40.

\section{Extended English Summary}

As a result of industrialization and computerization, people have had more opportunities than before to participate in leisure activities. This process led to the understanding of the importance of the free time area and to increase the interest in this area. The perception of the importance of leisure time and the idea of its steady progression rather than work-related values is born out of contemporary society. For this reason, leisure time is increasingly competing with workspaces. This situation causes inter-role conflicts, which makes the work-leisure conflict research important (Tsaur, Liang \& Hsu, 2012). Because work and leisure are two completely different aspects of life. As both are limited by personal time and energy, they may conflict or compete (Lin, Wong \& Ho, 2013; Wong \& Lin, 2007).

Work-leisure conflict is then defined as energy depletion that results in reduced time, energy, and leisure opportunities due to the dominance of service workers' job roles over other life roles or job demands of employees (Wong \& Lin, 2007). According to another definition, it is a form of interrole conflict that occurs when employees are exposed to a high workload that consumes valuable resources such as energy and time and renders them unable to fulfill their professional roles and has adequate leisure time activities (Mansour \& Tremblay, 2016). At the same time, the work-leisure conflict; The role density that emerges in the fields of work and leisure is characterized as a form of inter-role conflict with which it is not in harmony in relation to various issues. (Mansour \& Mohanna, 2018; Shi, Wang \& Li, 2021; Tsaur, Liang \& Hsu, 2012).

A person, who is described as a social being in many respects, must maintain his needs such as being approved, appreciated, supported, and respected, having a group and important achievements in the society throughout his life, and attaining these goals, and getting pleasure (Üren \& Çubukcioğlu, 2012). Employers' contribution to areas of support such as respect and appreciation of their employees in business life, and orientation that responds to their social and emotional needs, ensure that the employee is diligent and greedy in terms of maintaining his own existence in the organization. In addition, it will reveal an adopting stance in terms of ensuring the sustainability of the institution and its development. In this direction, it can be stated that they have interactive sustainability and relations (Erkoç, 2015).

The fact that the support factors perceived by the employees in preventing work-free time conflict are specific to the institution they work, brings the perceived organizational support factor to the fore. In this direction, responding to the social and emotional needs of the employee in the institution and paying attention to the well-being of the employees in the institution will cause the employee to work harder to realize the needs and goals of the institution and to move away from the negative attitude towards the institution (Kerse \& Karabey, 2017).

The common situation in perceived organizational support element; Perceived organizational support is the perception of providing value to what the employee does, prioritizing their welfare, and meeting their needs (Kerse \& Karabey, 2017). In this direction, it seems possible to limit the use of resources in free time and increase the workload, with a decrease in perceived organizational support. Employers' burdening their employees with work responsibilities during long working hours, even during weekends, is among the important factors that can cause work-free time conflict. In the scope of the study, while examining the levels of work-leisure conflict, the effect of perceived organizational support on work-leisure conflict was analyzed, at the same time, the differentiation status of various variables of work-leisure conflict and perceived organizational support were examined. 
This research, which examines the effect of the level of work-leisure conflict of the Ministry of Youth and Sports personnel on the perceived organizational support, has a descriptive structure in which the survey model is used. This model aims to reveal the existence or degree of change between two or more variables (Karasar, 2013). The study group of the research; In 2021, 140 (63.3\%) male and $81(36.7 \%)$ female Ministry of Youth and Sports personnel are working in Ankara. In addition to the personal information form, the "Work-Leisure Conflict Scale" and "Perceived Organizational Support Scale" were used in the data collection phase of the research.

Research findings in which the role of perceived organizational support in work-free time conflict was examined on Ministry of Youth and Sports personnel; It was determined that the participants experienced an average level of work-free time conflict, but the level of support they perceived from their organizations was above the average. Therefore, the findings reveal that the participants experience conflict between work and leisure time but receive social support in the organizational context. Another finding was obtained in the research of Sop (2014), and it was determined that there was a low level of work-leisure conflict in the research conducted on tourism employees. Another study, in line with the current finding, shows that the level of work and leisure time conflicts of hotel employees is moderate (İskender \& Yayl, 2017). Lin, Wong \& Ho (2015) and Zhao (2010) state that low workload is a factor in reducing work-leisure conflict.

As a result, it can be said that perceived organizational support will reduce work-free time conflict. It is thought that the support organizations receive from organizations should be designed to help establish a work-free time balance to increase employee productivity, improve service quality, and pave the way for the psychosocial improvement of employees. In this direction, it is among the suggestions that organizations should add elements that help reduce the work-free time conflict of employees to their policies and that they structure future policies in this context. At the same time, it is recommended to expand the field by researching work-free time conflict and perceived organizational support with different working groups. 